\title{
Arsenic and Antimony Doping: An Attempt to Deposit n-type CVD Diamond
}

\author{
Paul William May ${ }^{1}$, Martin Davey ${ }^{1}$, Keith N Rosser ${ }^{1}$, and Peter J Heard ${ }^{2}$ \\ ${ }^{1}$ School of Chemistry, University of Bristol, Cantock's Close, Bristol, BS8 1TS, United Kingdom \\ ${ }^{2}$ Interface Analysis Centre, University of Bristol, 121 St. Michael's Hill, Bristol, BS2 8BS, \\ United Kingdom
}

\begin{abstract}
We report the results of experiments that attempt to deposit n-type CVD diamond in a standard hot filament reactor using $1 \% \mathrm{CH}_{4} / \mathrm{H}_{2}$ gas mixtures, using (i) $\mathrm{AsH}_{3}$ as a gas phase source of arsenic, and (ii) evaporated $\mathrm{Sb}$ or $\mathrm{Sb}(\mathrm{Ph})_{3}$ as a source of antimony. SIMS measurements revealed that under these conditions, neither $\mathrm{Sb}$ nor As is incorporated into the diamond film, and the Raman spectra, electrical conductivity and crystallite morphology remain unchanged from that of undoped diamond. These experiments confirm the predicted low incorporation efficiency for As and Sb, and we conclude that doping CVD diamond with these elements cannot readily be achieved in this manner.
\end{abstract}

\section{INTRODUCTION}

Finding a suitable n-type dopant is a key requirement if CVD diamond is to play a major role in future electronic devices. Previous attempts to make n-type diamond by doping with elements such as N, S or P have either been unsuccessful, or have produced films with electrical characteristics that are not adequate for many proposed devices [1]. However, recent theoretical studies [2,3] have shown that if arsenic or antimony were to be incorporated substitutionally into a diamond lattice, they may act as useful n-type dopants. In particular, these studies predict that substitutional As and Sb should possess significantly shallower donor levels in diamond than substitutional phosphorus, being $\sim 0.4 \mathrm{eV}$ and $0.3 \mathrm{eV}$ below the conduction band minimum, respectively.

However, the large size of these atoms compared to that of carbon has led to the commonly held belief that their incorporation efficiency into the diamond lattice may be low. This, coupled with the high toxicity of As and Sb compounds, and the worry that they may permanently contaminate expensive CVD reactors, has meant that no experiments have been reported in the literature on their use as dopants for CVD diamond, despite them being quite commonly used in the Si industry. Implantation experiments using As have been reported [4,5] which show that about half of all the implanted As atoms do, indeed, lie at substitutional sites. Hunn et al. [6] implanted As into single crystal diamond and produced semiconducting layers with an activation energy of $0.41 \mathrm{eV}$. However, in order to make electrical contacts with the implanted layer, high doses of boron were also implanted followed by an annealing step which graphitised the surface. Thus, there remains the possibility that some of the conductivity may result from residual unintentional B-doping. Furthermore, all ion implantation studies introduce damage and defects into the lattice which cannot entirely be annealed out [4], and therefore such experiments cannot be taken as a reliable guide to the behaviour of As during CVD. 
The aim of this work, therefore, is to verify experimentally the assumption of low solubility in diamond for As and $\mathrm{Sb}$, and to determine if these elements can be utilised in the form of simple gaseous dopant species added to the process gas mixture during CVD - thereby imparting n-type semiconductivity into the diamond film.

\section{EXPERIMENT}

Diamond deposition occurred in a standard hot filament CVD reactor, using $1 \% \mathrm{CH}_{4}$ in $\mathrm{H}_{2}$ (total flow $200 \mathrm{sccm}$ ) as input gases, maintained at a process pressure of 20 Torr. The substrate had an area of $1 \times 1 \mathrm{~cm}^{2}$ and made from an intrinsic (undoped) single crystal (100) Si wafer. Prior to deposition the substrates were manually abraded with 1-3 $\mu \mathrm{m}$ diamond grit, and then cleaned with propan-2-ol. The substrate was placed in the chamber onto a resistive heater to give independent control of the substrate temperature. The filament was made from $0.25 \mathrm{~mm}$-diameter Ta wire, coiled into a $3 \mathrm{~mm}$-diameter helix of length $15 \mathrm{~mm}$, and was positioned at a height of $5 \mathrm{~mm}$ from the substrate surface. $6.75 \mathrm{~A}$ of alternating current was used to raise the temperature of the filament to $2400^{\circ} \mathrm{C}$, as measured by a two-colour optical pyrometer. The deposition time was $\sim 8 \mathrm{~h}$, with a diamond deposition rate around $0.5 \mu \mathrm{m} \mathrm{h}^{-1}$.

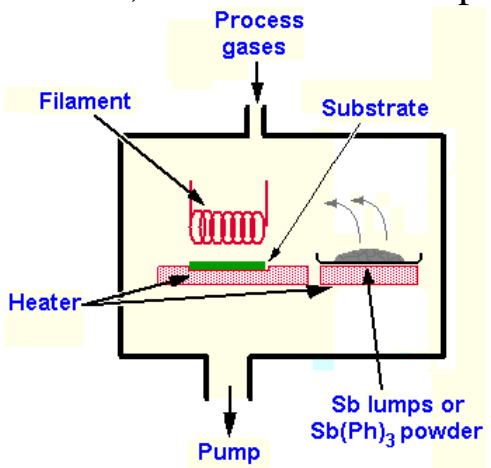

Figure 1. A schematic diagram of the hot filament reactor showing how the solid Sb lumps or $\mathrm{Sb}(\mathrm{Ph})_{3}$ powder were evaporated.

For doping experiments, the As and $\mathrm{Sb}$ were introduced into the chamber by different methods. Arsine gas $\left(\mathrm{AsH}_{3}\right)$ diluted in $\mathrm{H}_{2}$ was used as the source of As, and metered into the chamber using a mass flow controller. Different dilutions (from $15 \mathrm{ppm}$ to $0.5 \%$ ) were used to vary the gas phase As:C ratio in the reactor from $3000 \mathrm{ppm}$ to as high as 1:1. Similarly, we would have preferred to use stibine gas $\left(\mathrm{SbH}_{3}\right)$ as a source for antimony. However, this gas is very difficult to obtain commercially, and is unstable. Therefore, Sb was introduced as either triphenylantimony $\left(\mathrm{Sb}(\mathrm{Ph})_{3}\right)$ powder or as lumps of solid $\mathrm{Sb}$, which were placed into an independently-controlled heater within the chamber (see Fig.1). This allowed the material to vaporise at a controlled, steady rate throughout the deposition run. Measurements of the mass of the $\mathrm{Sb}$ or $\mathrm{Sb}(\mathrm{Ph})_{3}$ before (typically $\sim 0.5 \mathrm{~g}$ ) and after deposition allowed the evaporation rate, and hence the gas phase concentration of $\mathrm{Sb}$, to be calculated. Values used ranged from 5-1000 ppm with respect to total gas flow, which is equivalent to a gas phase $\mathrm{Sb}: \mathrm{C}$ ratio of $1000-200,000$ ppm (i.e. a maximum of $\mathrm{Sb}: \mathrm{C}=1: 5)$.

Films were analysed by scanning electron microscopy (SEM) to examine crystal morphology changes, laser Raman spectroscopy (325 nm excitation) to assess diamond quality, and secondary ion mass spectrometry (SIMS) depth profiling to determine the Sb and As content on the surface and in the bulk of the films. 


\section{RESULTS}

When using $\mathrm{AsH}_{3}$ gas, or evaporated $\mathrm{Sb}(\mathrm{Ph})_{3}$ or $\mathrm{Sb}$, it was noticed that after several deposition runs the chamber walls became coated in a shiny-grey layer of either pure As or $\mathrm{Sb}$. This coating did not appear on the substrate holder or within an area $\sim 2 \mathrm{~cm}$ diameter from the filament, but was confined to the cooler parts of the chamber. Although somewhat disconcerting from a health and safety point of view, these layers did confirm that As and Sb were successfully being introduced into the chamber in sufficient amounts for any changes to film properties to be apparent. Neither coating appeared to penetrate into the stainless steel reactor walls, and they were both readily removed by simply wiping with a cloth soaked in dilute aqueous nitric acid. Thus, it appears that As and $\mathrm{Sb}$ do not permanently contaminate a (cold-wall) CVD reactor, unlike boron, which, once introduced into a hot reaction chamber, diffuses into the walls and is extremely difficult to remove.

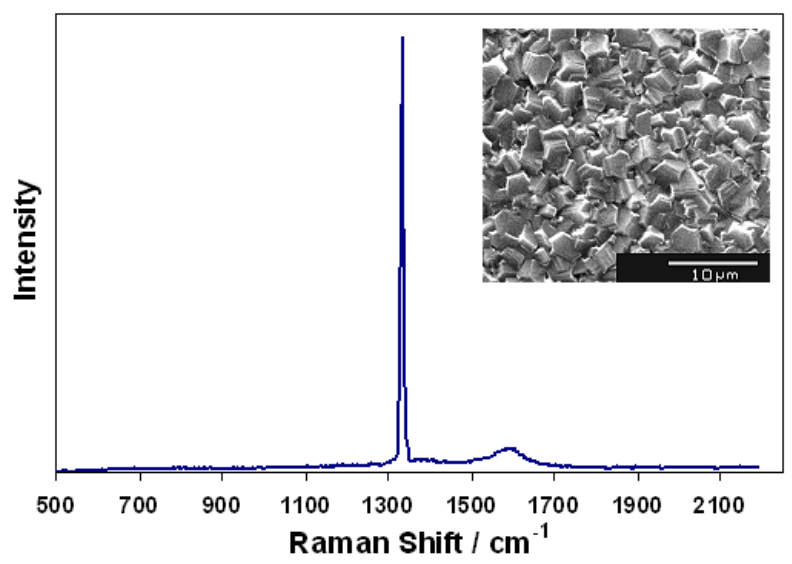

Figure 2. Laser Raman spectrum $(325 \mathrm{~nm})$ of the surface morphology of a CVD diamond film grown with a gas mixture of $1 \mathrm{sccm} \mathrm{CH}_{4}+0.2 \mathrm{sccm} \mathrm{AsH}_{3}+$ balance $\mathrm{H}_{2}$, showing the diamond $1332 \mathrm{~cm}^{-1}$ peak and a small $\mathrm{G}$ band. This spectrum is indistinguishable from the spectra taken from all the other films grown in the presence of As, Sb, and with no dopants. Inset is an example SEM picture showing the surface morphology to be microcrystalline, which again remained independent of As or Sb additions.

\section{$\underline{\text { Arsenic addition }}$}

Despite 30 deposition experiments, using $\mathrm{AsH}_{3}$ gas concentrations up to 1:1 with respect to methane, the diamond film morphology (Fig.2) and growth rate appeared unchanged from those of films grown without As addition. The Raman spectra (Fig.2), similarly, were identical to those of undoped films. Two-point and four-point probe measurements showed that the addition of $\mathrm{AsH}_{3}$ at any flow rate made no difference to the film conductivity, which remained constant with resistance values $\sim 10-100 \mathrm{M} \Omega$. SIMS analysis (Fig.3) showed that there was no As present in the bulk of the films (to within the detection limit), although there was a small amount present at the surface, probably as a result of contamination when the filament was turned off. This surface concentration can be estimated using Sparrow's relative sensitivity factors [7] to be $<0.08 \%$. It must be stressed that SIMS signals depend on many factors including instrument 
conditions, presence or absence of oxygen, and the matrix material in which the element is found, so this is very much an approximation.

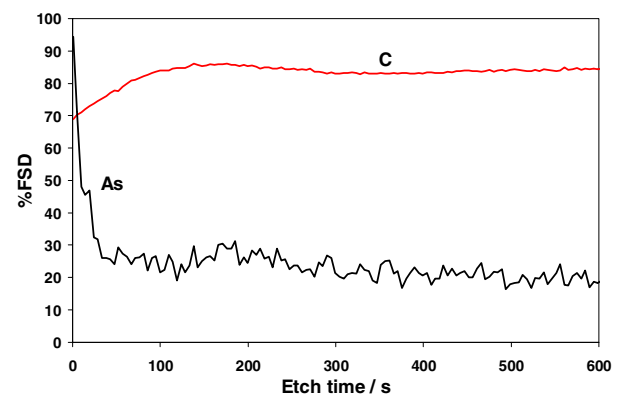

Figure 3. Positive SIMS depth profile of the CVD diamond film shown in Fig.2. The vertical axis is percentage of the full-scale deflection of counts for each species, which were 500 for As and 200,000 for C. There is As present on the surface of the film, but after only $20 \mathrm{~s}$ etching (equivalent to a depth of $\sim 1 \mathrm{~nm}$ ) the As signal drops to background levels. The background level at mass 75 , As, is about 100 counts per second (20\% FSD), and was also present on samples grown without As addition. This means this background signal is probably due to metastable polyatomic ions, and is not a signature of As. This indicates that the As is not incorporated into the bulk of the diamond, but is present only at the surface, probably as a contamination layer after the filament was switched off.

\section{$\underline{\text { Sb addition }}$}

The story is the same for antimony, whether it was vaporised from lumps of Sb or from $\mathrm{Sb}(\mathrm{Ph})_{3}$ powder. The Raman spectra, film morphology, growth rate, electrical resistivity of the films for all experiments with different $\mathrm{Sb}$ concentrations were identical to those of films grown without $\mathrm{Sb}$ addition. SIMS, again, showed no $\mathrm{Sb}$ to be present, either on the surface, or in the bulk of the films.

\section{CONCLUSIONS}

The experiments have shown that for these typical CVD conditions, antimony and arsenic do not readily incorporate into the growing diamond film, even when using extremely high As: $\mathrm{C}$ and $\mathrm{Sb}: \mathrm{C}$ ratios in the gas mixture. This provides experimental confirmation for the idea that these atoms are too large to readily substitute for carbon in the dense diamond lattice. However, the prospects for using these elements as n-type dopants are not entirely ruled out, since our experiments were confined to growth by hot filament reactors. In these reactors there is a localised heat source (the filament), which creates a steep thermal gradient pushing heavier atoms towards the colder chamber walls, where they condense and are removed from the reactive gas mixture. It is worth repeating these experiments, either in hot-walled reactors, which may prevent the condensation and loss of dopant atoms, or in microwave reactors where the thermal gradient is more gradual.

We believe that the high substrate temperature also proved a factor in preventing adsorption and subsequent incorporation of the volatile As and Sb atoms. As sublimes at only $887 \mathrm{~K}$ at atmospheric pressure, and therefore would probably not remain on the diamond surface (which is at about $1200 \mathrm{~K}$ ) long enough to chemically react. Sb evaporates at $1860 \mathrm{~K}$ at 
atmospheric pressure, but this temperature would be reduced considerably at CVD pressures of 20 Torr. Nevertheless, should the As or Sb species survive on the surface without immediate reevaporation, the next step to incorporation would be to form a chemical bond with the diamond lattice. However, since the bond enthalpies for $\mathrm{C}$-As and $\mathrm{C}-\mathrm{Sb}$ are significantly lower than that for C-C (see Table 1), the high temperature at the growing surface would readily break any such newly-formed bonds. Thus, another suggestion for future experiments might be to grow at lower substrate temperatures. Furthermore, impurities such as $\mathrm{P}$ are known to incorporate preferentially on the (111) surface of diamond, so growing under conditions which favour this growth surface (e.g. using (111) Si as a substrate and the correct gas mixture) may also be worthwhile exploring as an avenue to As incorporation.

Table 1. Average bond enthalpies at $298 \mathrm{~K}$ for the $\mathrm{M}-\mathrm{CH}_{3}$ bond [8] for various elements important in doping diamond.

\begin{tabular}{|c|c|c|c|c|c|}
\hline $\mathrm{M}$ & $\mathrm{C}$ & $\mathrm{B}$ & $\mathrm{P}$ & $\mathrm{As}$ & $\mathrm{Sb}$ \\
\hline$\Delta H /\left(\mathrm{kJ} \mathrm{mol}^{-1}\right)$ & 358 & 365 & 276 & 229 & 214 \\
\hline
\end{tabular}

\section{ACKNOWLEDGMENTS}

The authors would like to thank Professor Mike Ashfold and other members of the Bristol diamond group for useful discussions and Mr Adrian Stephenson for assistance with handling arsine gas.

\section{REFERENCES}

1. R. Kalish, Diamond Relat. Mater. 10, (2001) 1749.

2. S.J. Sque, R. Jones, J. P. Goss and P. R. Briddon, Phys. Rev. Letts. 92 (2004) 017402.

3. J.P. Goss, P.R. Briddon, R. Jones, S. Sque, Diamond Relat. Mater. 13 (2004) 684.

4. J.G. Correia, J.G. Marques, E. Alves, D. Forkel-Wirth, S.G. Jahn, M. Restle, M. Dahner, H. Hofsäss, K. Bharuth-Ram, ISOLDE Collaboration, Nucl. Instrum. Methods Phys. Res., Sect. B 127-128, (1997) 723.

5. H. Quintel, K. Bharuth-Ram, H. Hofsäss, M. Restle, C. Ronning, Nucl. Instrum. Methods Phys. Res., Sect. B 118, (1996) 72.

6. J.D. Hunn, N. R. Parikh and M. L. Swanson, R. A. Zuhr, Diamond Relat. Mater. 2 (1993) 847.

7. G.R. Sparrow, "Quantitative SIMS approximations for general applications in surface analysis". 25th Annual conference on mass spectroscopy and allied topics, (Washington DC., 1977).

8. M.E. O’Neill, K. Wade, in Comprehensive organometallic chemistry, ed. G. Wilkinson, F.G.A. Stone, E.W. Abel, Vol.1, p.5 (Pergamon, Oxford, 1982). 